\title{
Natura cosméticos: quando é virtuoso ser virtual
}

\section{Yara Rezende}

\section{Resumo}

Descreve a filosofia, o histórico de implantação e as funções da biblioteca virtual da Natura Cosméticos S.A., considerado o primeiro sistema virtual de informações em empresa do Brasil. Devido ao vertiginoso crescimento da empresa desde o início de sua atuação no mercado internacional, buscou-se a definição de uma estrutura de sustentação informativa que auxiliasse $o$ aprimoramento dos produtos $e$ processos e trouxesse informação sobre 0 que de mais moderno e inovador estivesse acontecendo na cosmética mundial. Além disso, buscava-se uma metodologia que também organizasse, sistematizasse e disponibilizasse a informação com rapidez e critérios seletivos de pertinência e relevância. Acreditava-se ser ineficaz a repetição do velho paradigma da biblioteca interna em um cenário de globalização de mercados no qual o acesso à informação não deveria estar limitado à informação que pudesse ser armazenada em uma sala de biblioteca. Mais importante do que ter a informação seria saber onde encontrá-la de maneira rápida e eficaz, porque guardar não significa dispor quando se necessita $e$ guardar tem um custo geralmente subestimado quando da criação de sistemas que pretendam ser efetivos quanto à prospecção e difusão de informações. $O$ foco de atuação do Centro de Informações Bibliográficas da Natura é o acesso externo à informação em detrimento do acervo interno de informação. Descreve as características, produtos e atividades desse sistema virtual de informações.

\section{Palavras-chave}

Biblioteca virtual; Empresas; Sistema referencial de informações.

\section{A EMPRESA}

A Natura iniciou suas atividades em 1969 como uma modesta loja de cosméticos e de consultoria personalizada de tratamento de beleza com sete funcionários. Em 1980, eram 200 funcionários e 2 mil consultoras espalhadas pelo país para a revenda de produtos e consultoria de tratamento. Chegou a 1990 com 1800 funcionários e 50 mil consultoras, e inicia 1997 como a maior empresa brasileira de cosméticos, com 3 mil funcionários, 145 mil consultoras no Brasil e cerca 10 mil na América Latina.

Nos últimos 10 anos, saltou de um faturamento de US\$76 milhões anuais para US\$ 836 milhões em 1996 com 61 miIhões de unidades vendidas, graças a uma base sustentada no desenvolvimento tecnológico de produtos de última geração no segmento de higiene pessoal.

Parte significativa desse faturamento está sendo utilizada em pesquisa e desenvolvimento, visto em 1996 ter lançado praticamente um novo produto a cada três dias.

A Natura recebe cerca de 10 mil pedidos de produtos por dia, feitos por suas consultoras de todas as regiões do país, e detém hoje expressiva participação no mercado de cosméticos em geral.

Espera-se triplicar o volume de negócios nos próximos 10 anos, bem como aumentar a participação no exterior em mais sete paises, além dos atuais cinco.

Na base de cifras tão impressionantes estão produtos considerados de qualidade pelo consumidor, um sistema de comercialização direta (também conhe- cido como "venda pessoal") e uma estratégia de marketing que valoriza, além da venda de produtos, o desenvolvimento de uma imagem de marca associada a "conceitos".

Seus produtos procuram não manipular o público prometendo milagres de beleza; buscam, antes, valorizar a relação do indivíduo consigo mesmo e com o mundo, na busca de um "bem-estar"e de um "estar bem". Essa filosofia traduz-se no próprio slogan da empresa, "Natura, Verdade em Cosmética".

\section{O JEITO NATURA DE PENSAR A INFORMAÇÃO}

No início dos anos 90, em pleno crescimento e iniciando sua atuação no mercado internacional, a Natura começa a buscar a definição de uma estrutura de sustentação informativa para o desenvolvimento e aprimoramento dos seus produtos e processos. Algo que trouxesse para a empresa a informação sobre o que de mais moderno e inovador estivesse acontecendo não somente no mundo da cosmetologia, mas também da dermatologia, moda, fitoterapia, psicologia, marketing, processos industriais, enfim, em todas as áreas e aspectos relacionados ao seu negócio.

A dinâmica desse segmento - no qual a cada dia novos ativos químicos mais eficazes são descobertos, variáveis como tendências de moda e de estilo de vida fazem surgir e desaparecer linhas inteiras de produtos e novos concorrentes estrangeiros estão chegando ao país - sinalizava que a empresa precisava ter acesso rápido e diferenciado a maior quantidade e variedade possível de informações que Ihe possibilitasse antecipar tendências. 
Buscava-se uma metodologia ágil e flexível que propiciasse acompanhar a concorrência, a ciência e as tecnologias mundiais de maneira custo-efetiva, que repassasse informações ao corpo de pesquisadores e de analistas de marketing da empresa, com rapidez, e critérios seletivos de pertinência e relevância e que, ao mesmo tempo, organizasse, sistematizasse e disponibilizasse essa "massa de informação" dentro da empresa.

O que se via nas empresas até então e que, pode-se dizer, vê-se até hoje, era o tradicional modelo de "biblioteca" ou "centro de informações/documentação" internos, onde uma coleção de livros e periódicos, pequena ou grande, propunha-se a suprir as necessidades de atualização tecnológica, muitas vezes acabando por tomar contornos de "biblioteca de lazer" ou de "biblioteca do grêmio" dos funcionários.

Ao mesmo tempo, era evidente para a Natura que, em um cenário de globalização de mercados e conseqüente globalização de concorrência, ganhos de tempo e de competitividade não poderiam ter limites. Da mesma maneira, o acesso à informação não deveria estar restrito e limitado à informação que pudesse ser armazenada em uma sala de biblioteca.

Adicione-se o fato de que o desenvolvimento tecnológico extremamente dinâmico faz com que montanhas de livros, papers e normas técnicas tornem-se obsoletos muito rapidamente. Assim, não teria sentido tratar a informação como um "bem durável", quando para essa realidade a informação ora se comporta como "insumo de produção", ora como "bem de consumo".

Mais importante do que ter a informação seria saber onde encontrá-la de maneira rápida e eficaz. "Guardar" não significa "dispor" quando se necessita e "guardar informação", no sentido de formar uma biblioteca dentro da empresa, tem um custo geralmente subestimado quando da criação de sistemas que pretendam ser efetivos quanto à prospecção e difusão de informações.

A Natura buscava uma solução que não implicasse criar estruturas internas que a desviasse do "foco" do seu negócio, que é produção e distribuição de cos- méticos, mas que possibilitasse ser estratégica em relação ao volume de informações a que pudesse ter acesso.

O "esforço de busca" da informação deveria estar direcionado para um espectro mais amplo quanto à probabilidade de sucesso, e as atividades ligadas a esse "esforço" deveriam ter baixo dispêndio de energia de maneira a possibilitar flexibilidade e agilidade de respostas diante das mudanças.

Pensando sempre em estímulos e ações que conduzissem a inovações, aperfeiçoamentos e ganhos, a Natura acreditava ser ineficaz a repetição do velho paradigma da "biblioteca interna". A administração de acervos deveria caber a quem tem competência nesse "foco de negócio", ou seja, às próprias bibliotecas já existentes, cujo objetivo é a preservação e a disponibilização da memória tecnológica. Afinal, o objetivo era acessar a informação, e não necessariamente tê-la armazenada internamente.

\section{O PROJETO DA BIBLIOTECA VIRTUAL DA NATURA}

No decorrer do ano de 1992, foi realizada, junto aos departamentos-chave da empresa, uma detalhada análise das necessidades dessas áreas quanto às tipologias, fontes e fluxo de informações para suporte ao desenvolvimento de produtos inovadores e de qualidade.

Foi feito um levantamento de como a informação, principalmente técnica e de mercado, veiculada em formato bibliográfico em seus diversos canais, fluía e era digerida dentro da empresa.

A conclusão desse estudo reiterou a percepção inicial que havia desencadeado o projeto. As áreas-chave da empresa apresentavam duas necessidades comuns:

1) ter acesso a informações mundiais da maneira mais ágil possível;

2) dispor internamente de uma estrutura responsável pela seleção, sistematização, disponibilização e organização de informações e documentos bibliográficos em tempo hábil e de maneira eficaz, independentemente de essa "organização" implicar a criação de uma biblioteca interna.
Assim, com a concepção de "acesso" em detrimento do "acervo", a Natura inicia uma política de incremento de acessos e intercâmbios com entidades dententoras de informação, em nível nacional e internacional, principalmente via bancos de dados on-line. Concomitantemente, desenvolve-se um sistema interno de bases de dados de referenciação das informações e documentos bibliográficos obtidos por meio desses acessos e intercâmbios.

Surgia, assim, aquele que é considerado hoje o primeiro sistema referencial de informações bibliográficas de empresa do país: a "biblioteca virtual", cujo acervo é o "mundo", não mais restrito às quatro paredes de uma biblioteca interna.

\section{A BIBLIOTECA VIRTUAL E SEUS PRODUTOS}

A Natura inicia 1993 implementando o projeto da biblioteca virtual a cargo de um coordenador e chega a 1997 com uma equipe composta de um supervisor com especialização em bases de dados, um analista de informações, um assitente técnico, um consultor para o desenvolvimento do projeto da "cosmetoteca mundial Natura" e um estagiário, todos com formação em biblioteconomia - um aumento de $400 \%$ no quadro de pessoal que reflete o crescimento e o aumento nas demandas da área.

Dentro de sua filosofia de acessar a informação, onde quer que ela se encontre, o Centro de Informações Bibliográficas, ou CIB-Natura, atua diretamente junto às áreas de criação e desenvolvimento de produtos, dando suporte a pesquisas de caráter técnico-científico, mercadológico e de acompanhamento da concorrência.

Dentre as atividades do CIB-Natura, destacam-se:

1) as pesquisas (ou acesso à informação propriamente dito);

2) o desenvolvimento e manutenção de bases de dados internas;

3) sistemas de alerta e disseminação de informações;

4) apoio logístico e controle de aquisição de documentos bibliográficos; 
5) disponibilização, em base de dados, dos documentos bibliográficos adquiridos;

6) gerenciamento do acervo do Centro de Memória Natura;

7) gerenciamento da Cosmetoteca Mundial Natura.

\section{AS PESQUISAS}

São quatro as tipologias de pesquisas feitas pelo CIB-Natura:

a) pesquisas ad hoc ou por tema;

b) pesquisas de referências bibliográficas predeterminadas;

c) pesquisas de "nome para produto";

d) pesquisas de registrabilidade de marcas.

a) Pesquisas ad hoc podem ser de dois tipos:

a) pesquisas que recuperam em uma primeira etapa uma bibliografia cujos itens serão selecionados pelo solicitante para recuperação dos textos integrais em uma segunda etapa;

b) pesquisas que recuperam a informação solicitada propriamente dita.

As pesquisas ad hoc são feitas mediante acesso a bases de dados privadas nacionais ou internacionais, a Internet, a coleção de CD-ROMs existente no CIB-Natura, ou diretamente por meio do acesso ao acervo de outras bibliotecas.

b) Pesquisas de recuperação de referências bibliográficas predeterminadas são realizadas pelos meios eletrônicos disponíveis, como catálogos coletivos em CD-ROM ou on-line, ou de consulta aos catálogos de outras bibliotecas, por telefone ou in loco. Quando as referências bibliográficas não são localizadas nos acervos geograficamente muito próximos, a comutação bibliográfica é feita em nível internacional, uma vez que os prazos dos serviços de nacionais de comutação não atendem à expectativa de espera da empresa; c) Pesquisas de "nome para produtos" ou de "apoio ao conceito de produtos" buscam criar nomes que estejam de acordo com o conceito, proposta e público-alvo dos novos produtos a serem lançados ou fundamentar o conceito desses produtos. Essas pesquisas são feitas em geral na Internet, ou em acervos de bibliotecas especializadas no assunto em questão.

d) Pesquisas de registrabilidade de marcas são feitas através do acesso on-line à base de dados de marcas registradas brasileiras e permite saber se os nomes escolhidos nas pesquisas de "nome para produtos" podem ser registrados no país como marca.

Os custos relativos às pesquisas são absorvidos pela área solicitante interessada.

\section{Desenvolvimento de bases de dados internas}

Em consonância com a filosofia de acessar informação em detrimento de armazená-la, o CIB-Natura desenvolve bases de dados de: 1) referenciação de acervos diversos existentes em qualquer área da empresa; 2) controle de rotinas; 3) informações propriamente ditas ou verdadeiras "bibliotecas virtuais".

As bases de dados são desenvolvidas e supervisionadas pelo CIB-Natura, mas a atualização ou input de dados cabe à área interessada. As bases estão disponíveis em rede apenas para os departamentos envolvidos com as informações contidas em cada uma das bases.

O sistema de banco de dados do CIBNatura conta hoje com 28 bases de dados.

\section{Sistemas de alerta e disseminação de informações}

É feito com base nos acervos das bibliotecas especializadas com as quais 0 CIB-Natura mantém intercâmbio, nas publicações recebidas na própria empresa, nos acessos à Internet e às redes privadas de informações.

Os alertas são feitos tanto para as áreas técnicas de desenvolvimento de produtos e de embalagens, como para as áreas de planejamento e logística, marketing, comércio exterior, entre outras.

\section{Apoio logístico e controle de aquisição de documentos bibliográficos}

O CIB-Natura mantém um sistema em base de dados para apoio e controle dos processos de compra de documentos bibliográficos, como livros, relatórios, publicações e assinaturas de periódicos. Esse sistema tem por objetivo facilitar ao departamento de compras da empresa a localização dos editores/fornecedores dos documentos bibliográficos a serem adquiridos e, por conseqüência, dinamizar o processo de compra/recebimento desses materiais.

Além disso, esse controle evita que, por desconhecimento, sejam adquiridos documentos idênticos ainda que para departamentos diferentes. Procura-se sempre maximizar o uso e minimizar as compras.

O CIB-Natura procura adquirir apenas aqueles documentos bibliográficos que não foram localizados para consulta ou empréstimo em outras bibliotecas ou a cujos conteúdos deva ter acesso imediato.

Sempre que possível o CIB-Natura repassa para outras bibliotecas especializadas os documentos bibliográficos de caráter genérico ou não-sigiloso aquiridos ou recebidos gratuitamente que não sejam mais utilizados. É mais custoefetivo acessar esses mesmos documentos em um outro acervo, do que mantêlos dentro da empresa.

Os custos relativos à compra de documentos bibliográficos sempre é alocado no departamento interessado ou solicitante.

\section{Disponibilização em base de dados dos documentos adquiridos}

Entre as tipologias de documentos bibliográficos existentes, as demandas do CIB-Natura estão concentradas em documentos de patente, livros técnicos, relatórios de mercado e artigos de periódicos ou de eventos.

Todo documento adquirido recebe tratamento técnico para a devida localização física e passa a fazer parte de uma base de dados que possibilita acessálos e localizá-los dentro da empresa. 
Dentro dessa base de dados é possível recuperar os documentos não apenas por dados referenciais como autor, título ou número, mas também e, principalmente, por todos os assuntos relacionados no sumário ou resumo do documento. Assim, é possível se ter acesso ao conteúdo do documento sem necessariamente manuseá-lo. A base de dados permite ainda saber em qual departamento o documento se encontra e se o mesmo está emprestado ou disponível para consulta.

Apesar de não existir dentro da Natura uma "biblioteca central", existem alguns departamentos que, por força de suas atividades, possuem pequenos acervos ou "bibliotecas", devidamente referenciados no sistema de banco de dados do CIB.

\section{Gerenciamento do acervo do centro de memória natura}

O Centro de Memória Natura é o setor responsável pelo resgate, tratamento, preservação e divulgação da história da empresa, ao cumprir suas atividadesfim, refletidas no dia-a-dia em diversos suportes, como documentos, imagens, registros sonoros e objetos.

O Centro de Memória contabiliza hoje um acervo com cerca de 42 mil imagens entre fotografias, cromos, negativos e slides, 10 mil documentos em suporte papel, 800 fitas de vídeo entre institucionais, apresentação de produtos e eventos internos, 100 fitas gravadas com depoimentos de pessoas e 10 mil peças entre produtos, troféus, brindes etc. Todo esse acervo encontra-se referenciado no sistema de banco de dados do CIB-Natura e não tem caráter de depósito ou museu. Trata-se de uma coleção dinâmica, utilizada diariamente como ferramenta de gestão por todos os departamentos da empresa.

Além do acervo propriamente dito, o Centro de Memória Natura oferece uma série de produtos que podem ser elaborados a partir dessas coleções, como históricos da empresa e departamentos, evolução das linhas de produtos, banco de depoimentos (história oral), exposições fotográficas e museológicas, "cases" de produtos, catálogos institucionais etc.

FIGURA 1

Ao longo dos seus quatro anos de existência, $O$ CIB Natura teve os seguintes índices de demandas

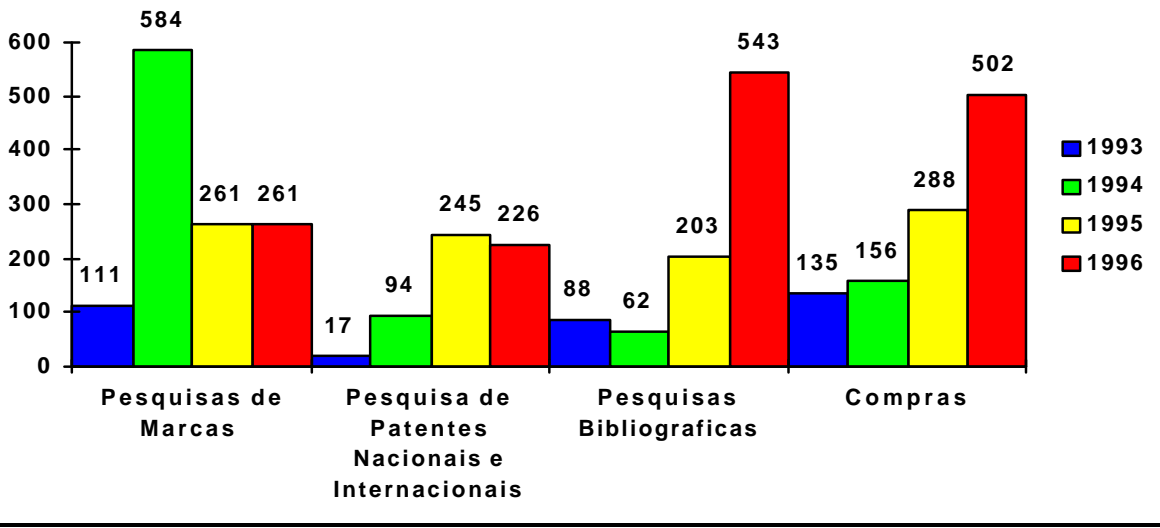

Por tratar-se de um setor que "trabalha a informação" gerada dentro da empresa, o Centro de Memória Natura é considerado "área afim por excelência" do CIB-Natura e, por isso, encontra-se sob a sua supervisão.

O setor conta hoje com uma equipe composta de três historiadores com especialização em arquivística e com a assessoria de um museólogo, um arquivista e um redator.

\section{Gerenciamento da Cosmetoteca Mundial Natura}

O CIB Natura é responsável pelo desenvolvimento, implantação e manutenção do acervo de produtos da concorrência nacional e internacional. Tem apresentado significativa demanda (figura 1).

Considerada a primeira "cosmetoteca" do país, esse acervo conta com cerca de 10 mil itens entre linhas de tratamento de rosto, corpo, cabelo, proteção solar, perfumaria, maquilagem, produtos infantis e produtos masculinos utilizados em estudos de formulação, embalagem, marketing etc.

Todos os produtos são acessáveis via base de dados independentemente do local de guarda física onde possam se encontrar.

\section{DA NATURA PARA O BRASIL}

Desde sua criação, o CIB Natura tem sido objeto de benchmark para empresas de áreas de atuação diversas em todo país, bem como objeto de seminários e congressos. Esse fato ratifica não só o pioneirismo da Natura em sua ousadia de inovar no campo da informação bibliográfica de apoio a negócios em face do que se praticava no país até então, como indica uma tendência internacional devida à nova ordem mundial. 


\section{BIBLIOGRAFIA CONSULTADA}

1. REZENDE, Yara; MARCHIORI, Patricia Zeni. Do Acervo ao Acesso: a perspectiva da biblioteca virtual em empresas. Ciência da Informação, Brasília, v. 23, n. 3, p. 349352, set./dez. 1994.

2. A BIBLIOTECA Virtual da Natura: rapidez com economia. Informática Hoje, São Paulo, n. 363, p. 19, 20 jul. 1994.

3. REZENDE, Yara. Sistemas de Informação: concepção lógica. Revista Brasileira de Biblioteconomia e Documentação, São Paulo, v. 25, n. 3/4, p. 11-17, jul./dez. 1992.
4. REZENDE, Yara. Biblioteca Técnica Requer Valorização. Diário Comércio \& IndústriaCaderno Consulta, São Paulo, v. 60, n. 16618, p. 2, 17 set. 1992.

5. REZENDE, Yara. A Falsa Utilidade da Biblioteca de Empresa. O Estado de São Paulo - Caderno Empresas, São Paulo, p. 2, 25 mar. 1992.

6. REZENDE, Yara. O Sistema de Informação na Indústria: enfoque sistêmico de um caso brasileiro. Revista Brasileira de Biblioteconomia e Documentação, São Paulo, v. 16, n. 3/4, p. 102-116, jul./dez. 1983.

\section{Natura cosméticos: when is virtuous to be virtual}

\begin{abstract}
Considered as the first virtual information system of a company in Brazil, it describes the Natura Cosméticos S. A virtual libraryphilosophy, implantation, history and functions. Due its vertiginous growing, followed by the begining of na informative sustentation structure which could support the products and processes improvement and which could bring the information about the most advanced discoveries in the worldwide cosmetology. The company was looking for a methodology that could also organize, systematize and dispose the information quickly through selective pertinence and significant criteria. The company believed inneficacious the internal library old paradigm repetition, face a market globalization scenery, where the information access should no be limited to the information the could be stored within a library room. More important than to have information should be to know where to find it quickly and efficiently, since information store does not means to have it when needed. Information store has a cost almost always underestimated during the creation of information systems which intend to be effective concerning the information prospection and diffusion. The Natura's Bibliographic Information Centre has it work focused to the external information access and not to the internal information collection. It describes the characteristics, activities and products of this virtual system.
\end{abstract}

\section{Keywords}

Virtual library; Companies; Referencial information systems.

\section{Yara Rezende}

Supervisora de Informações da Natura Cosméticos S.A.

Bacharel em biblioteconomia e documentação USP / ECA. 